\title{
OCNAtm: A biogeochemical model of Archean Earth
}

\author{
JULIA HORNE AND COLIN GOLDBLATT
}

University of Victoria

Presenting Author: juliahorne@uvic.ca

A new biogeochemical model for the early Earth with climate feedbacks illustrates the effects of increasing surface oxidation on the cycling of carbon and nitrogen species between atmosphere-ocean and geological reservoirs. This model is used to study the transition between the Neoarchean to Paleoproterozoic.

Previous biogeochemical models of the Proterozoic assumed a constant organic carbon burial fraction $\left(f_{\text {org }}\right)$, which is generally found to be 0.2 throughout the geologic record [1] [2]; maintaining $f_{\text {org }}$ enabled these researchers to suggest other mechanisms for driving the GOE, such as changing oxidation state of outgassed mantle volatiles or irreversible hydrogen escape. In contrast, an evaluation of carbon isotope fractionation suggests that $f_{\text {org }}$ may have propelled the GOE by increasing by a factor of 1.5 or 2 following the advent of photosynthetic metabolisms [3]. Our new model recreates the feedbacks between surface oxygenation and microbial remineralization to resolve this question of whether $f_{\text {org }}$ drove or followed the GOE.

This new biogeochemical model is also used to investigate the long-term nitrogen cycle. Recent evidence has shown increasing nitrogen concentrations in continents with decreasing age [4]. Geologic nitrogen sequestration is mediated by biologic assimilation and remineralization; our model recreates the biosphere-driven transfer of volatile nitrogen into geologic reservoirs, and further allows us to identify the primary mechanisms controlling the magnitude of sequestration, especially as this changed under increasing environmental oxidation.

\section{References}

[1] H. D. Holland. "Volcanic Gases, Black Smokers, and the Great Oxidation Event". In: Geochimica et Cosmochimica acta 66.21 (2002), pp. 3811-3826.

[2] D. C. Catling, K. J. Zahnle, and C. P. McKay. "Biogenic Methane, Hydrogen Escape, and the Irreversible Oxidation of Early Earth”. In: Science 293.5531 (2001), pp. 839-843.

[3] J. Krissansen-Totton, R. Buick, and D. C. Catling. "A Statistical Analysis of the Carbon Isotope Record from the Archean to Phanerozoic and Implications for the Rise of Oxygen". In: American Journal of Science 315.4 (2015), pp. 275-316.

[4] B. W. Johnson and C. Goldblatt. A Secular Increase in Continental Crust Nitrogen during the Precambrian. 2017. arXiv: 1709.02412 . 